\title{
COMPARATIVE STUDY ON THE REMOVAL OF ACID VIOLET BY ADSORPTION ON VARIOUS LOW COST ADSORBENTS
}

\author{
N. KANNAN* \\ S. MURUGAVEL
}

\author{
Department of Chemistry (PG), \\ Ayya Nadar Janaki Ammal College (Autonomous), \\ Sivakasi-626 124, Tamil Nadu, India \\ ${ }^{3}$ Indian Institute of Tropical Meteorology, Pune, India \\ *to whom all correspondence should be addressed:
}

Received: $27 / 01 / 07$

Accepted: 11/12/07

\begin{abstract}
The kinetic studies on the removal of Acid Violet-17 (AV) by adsorption on various adsorbents such as fly ash (FA), iron chromium oxide (ICO), lignite coal (LC), kapok fruit shell carbon (KC) and cashew nut shell carbon (CC) have been made and the results have been compared with that of commercial activated carbon (CAC). Effect of various experimental parameters has been investigated using batch adsorption technique at room temperature $\left(30 \pm 1^{\circ} \mathrm{C}\right)$. The percentage removal of $\mathrm{AV}$ increases with decrease in the initial concentration of $\mathrm{AV}$, initial $\mathrm{pH}$ and particle size of adsorbent and increases with increase in the contact time and dose of adsorbent. Adsorption data were modeled with the Freundlich and Langmuir adsorption isotherms and various first order kinetic equations at $30 \pm 1^{\circ} \mathrm{C}$. The kinetics of adsorption is found to be first order with intra particle diffusion as one of the rate determining steps. The adsorbent materials like iron-chromium oxide (ICO), kapok fruit shell carbon (KC) and cashew nut shell carbon (CC) could be employed as low cost adsorbents as alternative materials to CAC for the removal of AV.
\end{abstract}

KEYWORDS: Wastewater treatment, acid violet, Freundlich and Langmuir isotherms, kinetics of adsorption, intra particle diffusion.

\section{INTRODUCTION}

Industrial effluents largely affect the ground water and pollute the environment. Colour is the first contaminant to be recognized, since it is visible to human eye. So, effluent treatment for removal of colour is necessary to protect the environment and the aquatic life. Removal of dyes by conventional chemical and biological methods is not effective. Adsorption technique is followed for the removal of dyes. Activated carbon is widely used for the removal of dyes from effluent due to its effectiveness and versatility. Despite of its prolific use in water and wastewater industries commercial AC (CAC) remains an expensive material. This has led researchers to search for low cost materials as alternative adsorbent materials such as nut shell, fly ash, fruit stones and scrap tyres etc., as alternative to CAC (Pollard et al., 1992).

Attempts have been made to prepare AC from agricultural and industrial wastes. Preparation of ACs from a wide range of agro wastes for water purification has recently been reported by Pollard et al. (1992). ACs prepared from agricultural wastes have been used as adsorbents (Pollard et al., 1992; Deo and Ali, 1997; Kannan and Rajakumar, 2001; 2002; Kannan and Meenakshisundaram, 2001; 2002).

The present paper aims at assessing the ability of fly ash (FA), iron-chromium oxide (ICO), kapok fruit shell carbon (KC), cashew nut shell carbon (CC), and lignite coal (LC), as economically attractive low cost adsorbents for the removal of acid violet-17 (AV) and to study the kinetics of removal of AV. The objectives of this paper is to study the effect of various 
process parameters on the extent of removal of $A V$, to optimise the process parameters and to apply various adsorption isotherms and first order kinetic equations to the adsorption data.

\section{MATERIALS AND METHODS \\ Materials}

Commercial activated carbon (CAC) was procured from E Merck (India). Raw materials for the preparation of ACs such as kapok fruit shells and cashew nut shells were collected locally. They were washed, dried and cut into small pieces. The raw materials were carbonised (at $250^{\circ} \mathrm{C}$ ), thermally activated with $\mathrm{NaHCO}_{3}\left(\right.$ at $700^{\circ} \mathrm{C}$ ), acid digested with $2 \mathrm{~N}$ $\mathrm{HNO}_{3}$ solution (at $80^{\circ} \mathrm{C}$ for $2 \mathrm{~h}$ ), washed, dried and sieved into discrete particle size (Jayant sieve, India). FA and ICO were procured from Tuticorin Thermal power station and SPIC industry, Tuticorin, Tamil Nadu, respectively and lignite coal (LC) samples were collected from coal mines (Neyveli Lignite Corporation, Neyveli, Tamil Nadu). The materials were acid digested, washed, dried and sieved into discrete particle size (Jayant sieve, India) and stored. Adsorbent samples were thermally activated at $120^{\circ} \mathrm{C}$ for $2 \mathrm{~h}$. The dye (AV), supplied by BDH (India) was used as an adsorbate. Double Distilled (DD) water was used for preparing all the solutions and reagents. Thermostatic incubator shaker (Neolab, India) was used to maintain the temperature $\left(30 \pm 1^{\circ} \mathrm{C}\right)$.

\section{Adsorption studies}

A stock solution of AV (500 $\left.\mathrm{mg}^{-1}\right)$ was prepared and suitably diluted accordingly to the various required initial concentrations. Adsorption experiments were carried out at room temperature $\left(30 \pm 1^{\circ} \mathrm{C}\right)$ under batch mode (Kannan, 1991). The concentrations of the AV solutions before and after adsorption were estimated by measuring O.D. at $545 \mathrm{~nm}\left(\lambda_{\max }\right)$ with the help of UV-Visible spectrophotometer (ELICO, Model SL-159, India) and then interpolated into the standard curves. Exactly $50 \mathrm{ml}$ of $\mathrm{AV}$ solution of known initial concentration $\left(\mathrm{C}_{\mathrm{i}}\right)$ was shaken at constant agitation speed $(200 \mathrm{rpm})$ with required dose of adsorbent of a fixed particle size (75 microns) for a specific period of contact time (Table 1). The initial $\mathrm{pH}$ of the dye solution was adjusted to the required value by adding either $1 \mathrm{M} \mathrm{HCl}$ or $1 \mathrm{M} \mathrm{NaOH}$ solution. Initial $\mathrm{pH}$ values of dye solutions were noted with digital pen $\mathrm{pH}$ meter (Hanna instruments, Portugal). After equilibration, the final concentration $\left(\mathrm{C}_{\mathrm{f}}\right)$ of $\mathrm{AV}$ was measured by using a UV-Visible spectrophotometer (ELICO, Model SL-159, India). The values of percentage removal and the amount of dye adsorbed were calculated using following relationships:

$$
\begin{aligned}
& \text { Percentage removal }=\frac{C_{i}-C_{f}}{C_{i}} \times 100 \\
& \text { Amount adsorbed } q_{e}=\frac{C_{i}-C_{f}}{m}
\end{aligned}
$$

where, $C_{i}=$ initial concentration $(\mathrm{ppm})$

$\mathrm{C}_{\mathrm{f}}=$ final concentration $(\mathrm{ppm})$

$\mathrm{m}=$ mass of adsorbent $\left(\mathrm{g} \mathrm{I}^{-1}\right)$

Control experiments were carried out and the average values of duplicate runs were obtained and analysed (Error: $\pm 1-2 \%$ for percentage removal and $\pm 0.005-0.01 \mathrm{mg} \mathrm{g}^{-1}$ for amount adsorbed).

\section{RESULTS AND DISCUSSION}

The adsorption experiments were carried out at different experimental conditions (Table 1) and the results obtained are discussed below:

\section{Effect of initial concentration}

The effect of initial concentration of Acid Violet-17 (AV) on the extent of removal of AV (in terms of percentage removal and amount adsorbed (q) on various adsorbents were studied. The relevant data are given in Table 2. The percentage removal was found to decrease exponentially, while the amount of dye adsorbed increased exponentially with the increase in initial concentration of $\mathrm{AV}$. This indicates a decrease in adsorption, which is attributed due to 
the lack of available active sites required for the high initial concentration of AV. Similar results have been reported in literature on the extent of removal of dyes (Annadurai and Krishnan, 1996; Kannan and Meenakshisundaram, 2001; 2002; Deo and Ali, 1997; McKay et al., 1985), metal ions (Kannan and Rajakumar, 2001; 2002) and carboxylic acids (Kannan and Karuppasamy, 1998; Kannan and Xavier, 2001). The optimum initial concentration of dye solution (AV) was fixed for various adsorption systems and given in Table 1.

Table 1. Experimental conditions of adsorption experiment for the removal of AV by various adsorbents at $30^{\circ} \mathrm{C}$

\begin{tabular}{|c|c|c|c|c|c|c|c|}
\hline S.No. & Variation & Adsorbents & $\begin{array}{l}\text { Initial dye } \\
\text { concentration } \\
\text { (ppm) }\end{array}$ & $\begin{array}{l}\text { Dose } \\
\left(g^{-1}\right)\end{array}$ & $\begin{array}{l}\text { Contact } \\
\text { time } \\
\text { (min) }\end{array}$ & Initial pH & $\begin{array}{l}\text { Particle size } \\
\text { of } \\
\text { absorbents } \\
(\mu \mathrm{m})\end{array}$ \\
\hline $\mathrm{I}$ & $\begin{array}{l}\text { Initial dye } \\
\text { concentra- } \\
\text { tion }\end{array}$ & $\begin{array}{l}\text { CAC } \\
\text { FA,ICO,KC,CC,LC }\end{array}$ & $\begin{array}{l}115-145 \\
6-12\end{array}$ & $\begin{array}{l}\text { FA - } 10 \\
\text { Other } \\
\text { adsorbents - } 2\end{array}$ & 30 & $\begin{array}{l}\text { solution } \\
\mathrm{pH}^{*}\end{array}$ & 75 \\
\hline II & Contact time & $\begin{array}{l}\text { CAC } \\
\text { FA,ICO,KC,CC,LC }\end{array}$ & $\begin{array}{l}\text { CAC - } 140 \\
\text { Other } \\
\text { adsorbents - } 20\end{array}$ & $\begin{array}{l}\text { FA - } 10 \\
\text { Other } \\
\text { adsorbents - } 2\end{array}$ & $5-60$ & $\begin{array}{l}\text { solution } \\
\mathrm{pH}^{*}\end{array}$ & 75 \\
\hline III & Dose & $\begin{array}{l}\text { CAC } \\
\text { FA,ICO,KC,CC,LC }\end{array}$ & $\begin{array}{l}\text { CAC - } 140 \\
\text { Other } \\
\text { adsorbents - } 20\end{array}$ & $\begin{array}{l}\text { CAC - } 2-3.2 \\
\text { FA - } 8-20 \\
\text { ICO,KC,CC,LC - } \\
1-7\end{array}$ & 40 & $\begin{array}{l}\text { solution } \\
\mathrm{pH}^{*}\end{array}$ & 75 \\
\hline IV & Initial $\mathrm{pH}$ & $\begin{array}{l}\text { CAC } \\
\text { FA,ICO,KC,CC,LC }\end{array}$ & $\begin{array}{l}\text { CAC - } 140 \\
\text { Other } \\
\text { adsorbents - } 20\end{array}$ & $\begin{array}{l}\text { FA - } 10 \\
\text { Other } \\
\text { adsorbents - } 2\end{array}$ & 40 & $4-8$ & 75 \\
\hline $\mathrm{V}$ & $\begin{array}{l}\text { Particle size } \\
\text { of } \\
\text { absorbents }\end{array}$ & $\begin{array}{l}\text { Other than CAC } \\
\text { FA,ICO,KC,CC,LC }\end{array}$ & $\begin{array}{l}\mathrm{FA}, \mathrm{ICO}, \mathrm{KC}, \mathrm{CC}, \\
\mathrm{LC}-20\end{array}$ & $\begin{array}{l}\text { FA - } 10 \\
\text { Other } \\
\text { adsorbents - } 2\end{array}$ & 40 & $\begin{array}{l}\text { solution } \\
\mathrm{pH}^{*}\end{array}$ & $75-250$ \\
\hline $\mathrm{VI}$ & $\begin{array}{l}\text { lonic } \\
\text { Strength } \\
\text { Range } \\
(0.05-0.3)\end{array}$ & $\begin{array}{l}\text { CAC } \\
\mathrm{FA}, \mathrm{ICO}, \mathrm{KC}, \mathrm{CC}, \mathrm{LC}\end{array}$ & $\begin{array}{l}\text { CAC - } 140 \\
\text { Other adsorbents } \\
-20\end{array}$ & $\begin{array}{l}\text { FA - } 10 \\
\text { Other } \\
\text { adsorbents - } 2\end{array}$ & 40 & $\begin{array}{l}\text { solution } \\
\mathrm{pH}^{*}\end{array}$ & 75 \\
\hline
\end{tabular}

*Solution $\mathrm{pH}: 6.6$

\section{Adsorption isotherms}

The adsorption data were analysed with the help of the following linearised forms of Freundlich and Langmuir isotherms (Adamson, 1960):

Freundlich isotherm: $\log q_{e}=\log K+\frac{1}{n} \log C_{e}$

where, $\mathrm{K}=$ adsorption capacity

$$
\text { Langmuir isotherm : } \frac{C_{e}}{q_{e}}=\frac{1}{Q_{o} b}+\frac{C_{e}}{Q_{o}}
$$

$(1 / n)=$ order/intensity of adsorption

$\mathrm{q}_{\mathrm{e}}=$ amount of $\mathrm{AV}$ adsorbed per unit mass of adsorbent $\left(\mathrm{mg} \mathrm{g}^{-1}\right)$

$\mathrm{C}_{\mathrm{e}}=$ equilibrium concentration of dye (ppm)

$\mathrm{Q}_{\mathrm{o}}=$ monolayer (maximum) adsorption capacity $\left(\mathrm{mg} \mathrm{g}^{-1}\right)$

$\mathrm{b}=$ Langmuir constant related to energy of adsorption $\left(\mathrm{Img}^{-1}\right)$

The values of Freundlich and Langmuir parameters have been obtained, respectively, from the linear correlation between the values of (i) $\log q_{e}$ and $\log C_{e}$ and (ii) $\left(C_{e} / q_{e}\right)$ and $C_{e}$ (Table 3). 
Table 2. Effect of Process parameters on the extent of removal of AV by various adsorbent at $30^{\circ} \mathrm{C}$

\begin{tabular}{|c|c|c|c|c|c|c|c|}
\hline $\begin{array}{c}\text { Process } \\
\text { Parameter } \\
\text { varied }\end{array}$ & $\underset{\text { ter }^{*}}{\text { Parame }}$ & CAC & FA & ICO & KC & CC & LC \\
\hline \multirow{2}{*}{$\begin{array}{l}\text { Initial } \\
\text { concentration } \\
\text { (ppm.) }\end{array}$} & $\% R$ & $96.94-91.93$ & $68.55-37.11$ & $59.12-51.26$ & $33.96-21.38$ & $16.14-13.00$ & $27.67-18.76$ \\
\hline & $q$ & $55.74-66.65$ & $0.411-0.445$ & $1.774-3.075$ & $1.019-1.283$ & $0.484-0.780$ & $0.830-1.126$ \\
\hline \multirow{2}{*}{$\begin{array}{l}\text { Contact time } \\
\text { (min.) }\end{array}$} & $\% \mathrm{R}$ & $79.78-95.55$ & $9.120-27.99$ & $38.36-42.77$ & $22.01-31.45$ & $3.460-15.41$ & $15.09-27.04$ \\
\hline & $q$ & $55.85-66.89$ & $0.182-0.560$ & $3.836-4.277$ & $2.201-3.145$ & $0.346-1.541$ & $1.509-2.704$ \\
\hline \multirow{2}{*}{$\begin{array}{l}\text { Dose } \\
\left(\mathrm{g} \mathrm{l}^{-1}\right)\end{array}$} & $\% \mathrm{R}$ & $92.41-98.56$ & $79.20-89.50$ & $24.84-84.91$ & $18.24-49.37$ & $10.38-31.76$ & $14.47-58.49$ \\
\hline & $q$ & $64.69-43.12$ & $0.865-0.670$ & $4.969-2.426$ & $3.648-1.411$ & $2.075-0.907$ & $2.893-1.671$ \\
\hline \multirow[t]{2}{*}{ Initial pH } & $\% \mathrm{R}$ & $94.16-92.14$ & $71.70-0.630$ & $59.12-22.01$ & $42.77-24.53$ & $23.27-9.430$ & $24.21-19.81$ \\
\hline & $q$ & $65.91-64.50$ & $1.434-0.013$ & $5.912-2.201$ & $4.277-2.453$ & $2.327-0.943$ & $2.421-1.981$ \\
\hline \multirow{2}{*}{$\begin{array}{l}\text { Particle size (in } \\
\text { micron) }\end{array}$} & $\% \mathrm{R}$ & ....... & $22.64-2.200$ & $42.45-18.87$ & $28.93-4.720$ & $12.58-5.660$ & $20.13-4.400$ \\
\hline & $q$ & ........ & $0.453-0.044$ & $4.245-1.887$ & $2.893-0.472$ & $1.258-0.566$ & $2.013-0.440$ \\
\hline \multirow{2}{*}{$\begin{array}{l}\text { lonic Strength } \\
\text { Range }(0.05- \\
0.3)\end{array}$} & $\% R$ & $92.59-98.97$ & $22.01-33.33$ & $42.45-63.52$ & $28.30-63.21$ & $13.52-36.48$ & $20.75-36.48$ \\
\hline & $q$ & 64.81-69.28 & $0.440-0.667$ & $4.245-6.352$ & $2.830-6.321$ & $1.352-3.648$ & $2.075-3.648$ \\
\hline
\end{tabular}

Table 3. Freundlich and Langmuir parameters of adsorption isotherms for the removal of AV by various adsorbents at $30^{\circ} \mathrm{C}$

\begin{tabular}{|c|c|c|c|c|c|c|c|}
\hline Model & Parameter & CAC & FA & ICO & $\mathrm{KC}$ & CC & LC \\
\hline \multirow{4}{*}{$\begin{array}{l}\text { Freundlich } \\
\text { isotherm }\end{array}$} & K-values & 47.00 & 0.396 & 1.007 & 0.592 & 0.157 & 0.513 \\
\hline & Slope $(1 / \mathrm{n})$ & 0.140 & 0.051 & 0.624 & 0.354 & 0.680 & 0.357 \\
\hline & $\begin{array}{l}\text { Correlation } \\
\text { coefficient }(r)\end{array}$ & 0.981 & 0.935 & 0.995 & 0.964 & 0.993 & 0.950 \\
\hline & $\Delta \mathrm{q}(\%)$ & 0.006 & 0.003 & 0.014 & 0.036 & 0.016 & 0.044 \\
\hline \multirow{5}{*}{$\begin{array}{l}\text { Langmuir } \\
\text { isotherm }\end{array}$} & $Q_{0}$ & 72.01 & 0.454 & 6.493 & 1.780 & 1.975 & 1.523 \\
\hline & $\mathrm{b}$ & 0.917 & 3.803 & 0.148 & 0.285 & 0.061 & 0.303 \\
\hline & $\begin{array}{l}\text { Correlation } \\
\text { coefficent }(r)\end{array}$ & 0.999 & 0.999 & 0.976 & 0.994 & 0.963 & 0.991 \\
\hline & $\Delta \mathrm{q}(\%)$ & 0.009 & 0.010 & 0.026 & 0.046 & 0.022 & 0.030 \\
\hline & $10^{2} R_{L}$ & 0.837 & 2.983 & 43.60 & 27.50 & 64.90 & 27.60 \\
\hline
\end{tabular}

In order to compare the validity of each model (isotherm) more efficiently a normalised standard deviation, $\Delta \mathrm{q}(\%)$ is calculated using the following equation:

$$
\Delta q(\%)=100 \times\left[\frac{\sum\left(\frac{q_{t}^{\exp }-q_{t}^{\text {cal }}}{q_{t}^{\text {exp }}}\right)^{2}}{n-1}\right]^{\frac{1}{2}}
$$

where, the superscripts, exp. and cal. are the experimental and calculated values of $\mathrm{q}_{\mathrm{t}}$ viz., the amount adsorbed at different time $\mathrm{t}$ and $\mathrm{n}$ is the number of observations.

The $\Delta q(\%)$ values are also given in Table 3. Based on the low values of $\Delta q(\%)$, it is concluded that the adsorption of $\mathrm{AV}$ can be best described by the Langmuir adsorption isotherm. Langmuir isotherm plots are shown in Figure 1. The monolayer adsorption capacities $\left(Q_{0}\right)$ of the adsorbents are found to be of the order given below:

$$
\mathrm{FA}<\mathrm{LC}<\mathrm{KC}<\mathrm{CC}<\mathrm{ICO}<\text { CAC }
$$

Further, the essential characteristics of the Langmuir isotherm can be described by a Separation factor, $R_{L}$, which is defined by the following equation (Hall, et al., 1966): 


$$
\mathrm{R}_{\mathrm{L}}=\frac{1}{1+\mathrm{bC}_{\mathrm{i}}}
$$

where, $C_{i}=$ optimum initial concentration of $A V\left(\mathrm{mg} \mathrm{l}^{-1}\right)$

$\mathrm{b}=$ Langmuir constant $\left(\mathrm{Img}^{-1}\right)$.

The values of separation factor, $R_{\mathrm{L}}$, indicate the nature of the adsorption process as given below:

$\begin{array}{ll}R_{L} \text { values } & \text { Nature of adsorption process } \\ R_{L}>1 & \text { Unfavourable } \\ R_{L}=1 & \text { Linear } \\ 0<R_{L}<1 & \text { Favourable } \\ R_{L}=0 & \text { Irreversible }\end{array}$

In the present study, the values of $\mathrm{R}_{\mathrm{L}}$ (Table 3 ) are observed to be fraction i.e., in the range of zero to one (0.0298-0.649), which indicate that the adsorption process is favourable for all these adsorbents.

\section{Effect of contact time}

The effect of contact time on the amount of dye adsorbed was observed at the optimum initial concentration of dye. The relevant data are also given in Table 2. The extent of removal of AV by these adsorbents is found to increase and reach a maximum value with increase in contact time. The relative increase in the extent of removal of dye after $40 \mathrm{~min}$. of contact time is not significant and hence it is fixed as the optimum contact time. Similar results have been reported in literature for the removal of dyes (Deo and Ali, 1997; Kannan and Meenakshisundaram, 2002; McKay, 1985) metal ions (Kannan and Rajakumar, 2001; 2002) and carboxylic acids (Kannan and Karuppasamy, 1998; Kannan and Xavier, 2001).

\section{Kinetics of adsorption}

The kinetics and dynamics of adsorption of $A V$ on various adsorbents have been studied by applying the various first order kinetic equations (Kannan and Rajakumar, 2001; 2002; Kannan and Meenakshisundaram, 2001; 2002):

Natarajan and Khalaf equation:

$$
\log \frac{C_{i}}{C_{t}}=\frac{k}{2.303} t
$$

Lagergren equation:

$$
\begin{array}{ll}
\text { Lagergren equation: } & \log \left(q_{e}-q_{t}\right)=\log q_{e}-\frac{k}{2.303} t \\
\text { Bhattacharya and Venkobachar equation: } & \log [1-U(T)]=-\frac{k}{2.303} t
\end{array}
$$

where:

$C_{i}$ and $C_{t}=$ concentration of $A V$ at time zero and time $t$, respectively $\left(\mathrm{mg} \mathrm{l}^{-1}\right)$

$\mathrm{q}_{\mathrm{e}}$ and $\mathrm{q}_{\mathrm{t}}=$ amount of $\mathrm{AV}$ adsorbed at equilibrium time and time $\mathrm{t}$, respectively $\left(\mathrm{mg} \mathrm{g}^{-1}\right)$

$U(T)=\left[\left(C_{i}-C_{t}\right) /\left(C_{i}-C_{e}\right)\right]$

$\mathrm{C}_{\mathrm{e}}=$ equilibrium $\mathrm{AV}$ concentration $\left(\mathrm{mg} \mathrm{I}^{-1}\right)$

$\mathrm{k}=$ first order adsorption rate constant $\left(\mathrm{min}^{-1}\right)$.

The values of (i) $\log \left(C_{i} / C_{t}\right)$, (ii) $\log \left(q_{e}-q_{t}\right)$ and (iii) $\log [1-U(T)]$ were linearly correlated with time $(\mathrm{t})$. The values of first order rate constant, $\Delta \mathrm{q}(\%)$ and correlation coefficient (r-values) are given in Table 4. All the linear correlations were found to be statistically significant, indicating the applicability of these kinetic equations and the first order nature of the adsorption process of $\mathrm{AV}$ on these low cost adsorbents. The rate of adsorption is found to be high in ICO $(0.107$ $\left.\mathrm{min}^{-1}\right)$ and low in LC $\left(0.061 \mathrm{~min}^{-1}\right)$ as evidenced by k-values. Lagergren plots are shown in Figure 2. 


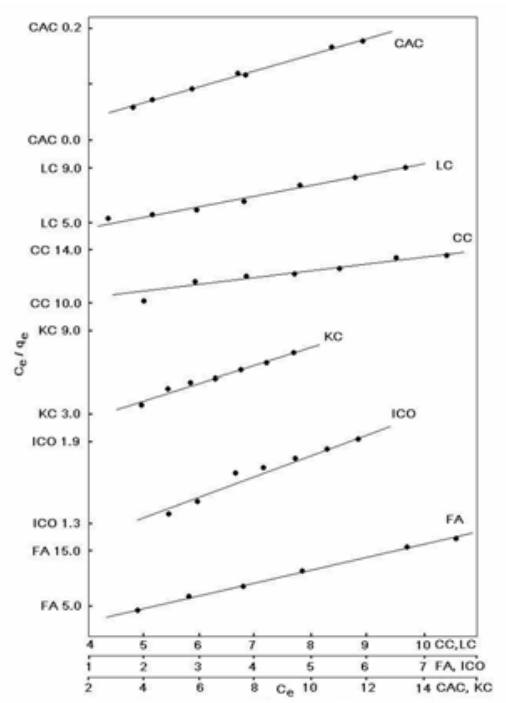

Figure 1. Langmuir isotherm plots for the removal of $\mathrm{AV}$ by adsorption on various adsorbents

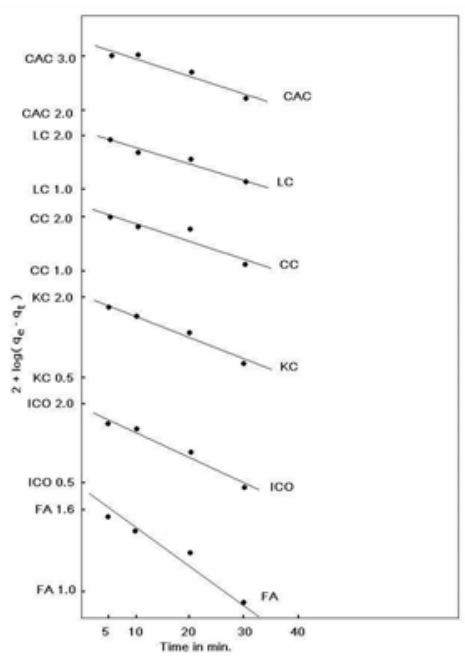

Figure 2. Lagergren plots for the removal of $\mathrm{AV}$ by adsorption on various adsorbents

\section{Intra particle diffusion model}

The possibility of intra particle diffusion process was explored by using the Weber and Morris intra particle diffusion model (Weber and Morris, 1964): $\quad q_{t}=k_{p} t^{1 / 2}+C$ where:

$\mathrm{q}_{\mathrm{t}}=$ amount of $\mathrm{AV}$ adsorbed at time, $\mathrm{t}\left(\mathrm{mg} \mathrm{g}^{-1}\right)$

$C=$ intercept

$\mathrm{k}_{\mathrm{p}}=$ intra particle diffusion rate constant $\left(\mathrm{mg} \mathrm{g}^{-1} \min ^{-1 / 2}\right)$.

Table 4. Statistical results of the application of the kinetic equations and models for AV dye by various adsorbent systems at $30^{\circ} \mathrm{C}$

\begin{tabular}{|c|c|c|c|c|c|c|}
\hline \multirow{2}{*}{ Parameter } & \multicolumn{6}{|c|}{ Carbon } \\
\hline & CAC & FA & ICO & $\mathrm{KC}$ & CC & LC \\
\hline \multicolumn{7}{|c|}{ I.Natarajan and Khalaf equation } \\
\hline $10^{2} \mathrm{k}$ & 3.311 & 0.452 & 0.133 & 0.227 & 0.222 & 0.244 \\
\hline r-value & 0.959 & 0.972 & 0.880 & 0.960 & 0.911 & 0.984 \\
\hline$\Delta \mathrm{q}(\%)$ & 22.90 & 22.80 & 60.01 & 50.35 & 27.37 & 43.72 \\
\hline \multicolumn{7}{|c|}{ II.Lagergren equation } \\
\hline $10^{2} \mathrm{k}$ & 7.472 & 5.566 & 10.71 & 9.477 & 8.398 & 6.112 \\
\hline r-value & 0.966 & 0.975 & 0.989 & 0.992 & 0.991 & 0.978 \\
\hline$\Delta q(\%)$ & 9.437 & 1.734 & 6.332 & 5.577 & 3.757 & 9.355 \\
\hline \multicolumn{7}{|c|}{ III.Bhatacharya and Venkobachar equation } \\
\hline $10^{2} \mathrm{k}$ & 7.472 & 5.566 & 10.71 & 9.477 & 8.398 & 6.112 \\
\hline r-value & 0.966 & 0.975 & 0.989 & 0.992 & 0.991 & 0.978 \\
\hline$\Delta q(\%)$ & 12.67 & 17.42 & 7.929 & 9.400 & 10.99 & 15.83 \\
\hline \multicolumn{7}{|c|}{ IV. Intra particle diffusion model } \\
\hline $10^{2} k_{p}$ & 239.5 & 7.488 & 8.490 & 17.05 & 21.16 & 19.50 \\
\hline Intercept & 50.15 & 0.012 & 3.699 & 1.896 & 0.065 & 1.113 \\
\hline r-value & 0.965 & 0.989 & 0.938 & 0.983 & 0.957 & 0.988 \\
\hline$\Delta q(\%)$ & 0.027 & 0.123 & 0.016 & 0.033 & 5.576 & 0.062 \\
\hline \multicolumn{7}{|c|}{ V. log (\% removal) vs log (time) } \\
\hline Slope & 0.088 & 0.485 & 0.049 & 0.144 & 0.570 & 0.213 \\
\hline Intercept & 1.831 & 0.608 & 1.550 & 1.245 & 0.246 & 1.031 \\
\hline r-value & 0.967 & 0.993 & 0.974 & 0.992 & 0.952 & 0.985 \\
\hline$\Delta \mathrm{q}(\%)$ & 64.77 & 16.45 & 54.03 & 54.01 & 54.43 & 53.93 \\
\hline
\end{tabular}


The values of $q_{t}$ were found to be linearly correlated with values of $t^{1 / 2}$. The $k_{p}$ values were calculated by using correlation analysis (Table 4). The r-values are found to be close to unity, indicating the application of this model. This reveals the presence of intra particle diffusion process (Weber and Morris, 1964; Deo and Ali, 1997). The calculated values of $k_{p}$ is maximum for CC (0.212) and minimum for ICO (0.008). This result indicates that the CC is more porous than the other low cost adsorbents. The intra particle diffusion plots are given in Figure 3 . The values of intercept (Table 4) give an idea about the boundary layer thickness i.e., the larger the intercept, the greater is the boundary layer effect (Deo and Ali, 1997; McKay, 1983). The intercept (C) value is maximum in ICO (3.699) and minimum in CC (0.065) indicating that the boundary layer effect is maximum in ICO and minimum in $\mathrm{CC}$, among the indigenously prepared carbons.

The correlation of the values of log (\% removal) and log (time) also resulting in linear relationship, which indicates that the process of intra particle diffusion is taking place in these adsorption system (Table 4). The divergence in the values of slope from 0.5 (min. - max. $=0.049-1.012$ ) indicates the presence of intra particle diffusion process as one of the rate limiting steps, besides many other processes controlling the rate of adsorption, all of which may be operating simultaneously (Deo and Ali, 1997).

\section{Effect of dose of adsorbent}

The effect of dose of adsorbent on the amount of AV adsorbed was studied (Table 2). The equilibrium value of amount adsorbed was observed to decrease with increase in dose of adsorbent. The percentage removal (Table 2) increases with increase in dose of adsorbent. This may be due to the increase in availability of surface active sites resulting from the increased dose and conglomeration of the adsorbent (Kannan and Karuppasamy, 1998). The amount of $\mathrm{AV}$ adsorbed was observed to vary exponentially in accordance with the fractional power term of the dose of adsorbent i.e. (dose) ${ }^{-n}$, where $n=$ fraction. The $n$-values ( $r$-values) are $\mathrm{CAC}=0.848$ (0.999), $\mathrm{FA}=0.27 \quad(0.990), \quad \mathrm{ICO}=0.3602 \quad(0.990), \mathrm{KC}=0.498 \quad(0.995)$, $\mathrm{CC}=0.3608(0.944)$ and LC=0.302 (0.909). The plots of log $\mathrm{q}_{\mathrm{e}} v s$ log (dose) were found to be linear $(r=$ unity). This suggests that the adsorbed species/solutes may either block the access to the internal pores or cause particles to aggregate and there by resulting in decrease in the availability of active sites for adsorption. Similar results have been noticed in literature for the removal of dyes (Deo and Ali, 1997; Kannan and Meenakshisundaram, 2002; McKay, 1985) metal ions (Kannan and Rajakumar, 2001; 2002) and carboxylic acids (Kannan and Karuppasamy, 1998; Kannan and Xavier, 2001).

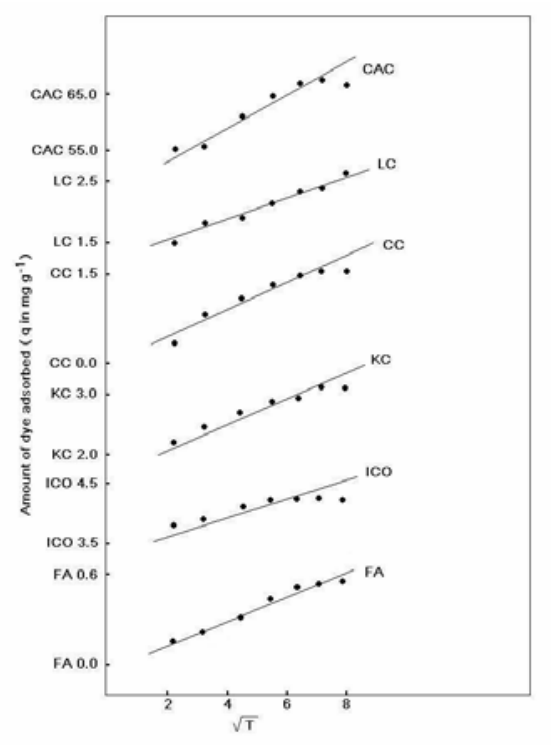

Figure 3. Intra particle diffusion plots for the removal of $A V$ by adsorption on various adsorbents

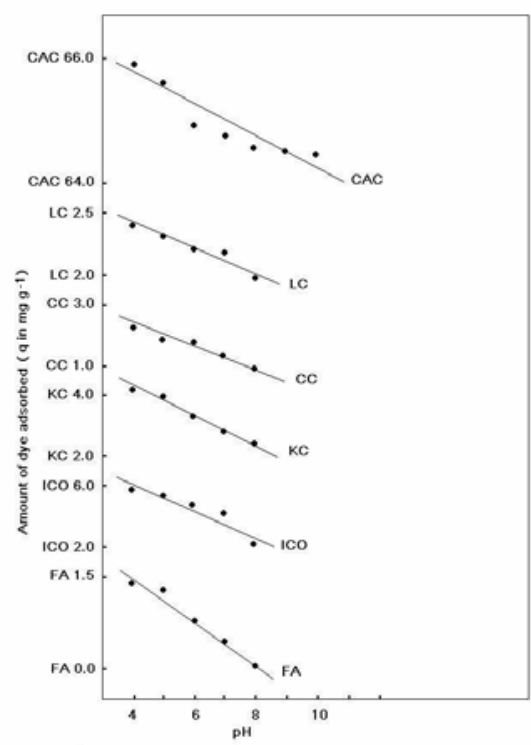

Figure 4. Effect of $\mathrm{pH}$ on the removal of $\mathrm{AV}$ by adsorption on various adsorbents 


\section{Effect of initial pH}

The effect of initial $\mathrm{pH}$ of the dye solution on the amount of $\mathrm{AV}$ adsorbed was studied by varying the initial $\mathrm{pH}$, under constant conditions of other process parameters (Table 2). The $\mathrm{pH}$ value changes slightly after adsorption and a decrease in $\mathrm{pH}$ value is noted $(\Delta \mathrm{pH}=\mathrm{pH}$ final $-\mathrm{pH}$ initial). The optimum $\mathrm{pH}$ value is fixed as 6.6. The results are shown in Figure 4. The increase in initial $\mathrm{pH}$, decrease the amount of $\mathrm{AV}$ adsorbed. The change in initial $\mathrm{pH}$ values of dye solution significantly affect the adsorption characteristics of acidic dye indicating that removal of $A V$ (Acidic dye) is enhanced by acidic solution.

\section{Effect of particle size of the adsorbent}

The amount of AV adsorbed increases with the decrease in particle size of the adsorbent. This is due to the increase in available surface area with the decrease in particle size. There exists a linear relationship between the amount of dye adsorbed and particle size, as evidenced by the r-value close to unity ( $r$-value for $F A=0.938, I C O=0.924, K C=0.912$, $C C=0.983$ and $L C=0.934$ ). Similar observations have been reported for the adsorption of dyes (Deo and Ali, 1997; Kannan and Meenakshisundaram, 2001; McKay et al., 1985; McKay, 1983).

\section{Effect of ionic strength}

The increase in the percentage of removal with increase in the ionic strength of electrolytes $\left(\mathrm{NaCl}, \mathrm{NaNO}_{3}\right.$ and $\left.\mathrm{Na}_{2} \mathrm{SO}_{4}\right)$ for the adsorbents (CAC, FA, ICO, $\mathrm{KC}, \mathrm{CC}$ and $\mathrm{LC}$ ) indicate that the adsorption is sensitive to the change in ionic strength, which indicate that electrostatic attraction is a significant mechanism for sorption process. The increase in adsorption with ionic strength may be due to the compression of the thickness of the diffused double layer (Vinod, 2004). Such compression may help the sorbent particle and sorbate species to approach each other more closely, by then the attractive forces become significant, leading to increased adsorption. These results indicate that electrostatic attraction plays a significant role in the removal of AV (Vinod, 2004).

\section{CONCLUSIONS}

Acid Violet-17 (AV) is found to adsorb strongly on the surface of carbons. The percentage removal of $A V$ increases with decrease in the initial concentration of the dye (AV), initial $\mathrm{pH}$ and particle size of adsorbent, and increases with increase in the contact time and dose of adsorbent. Adsorption data were modeled with the Freundlich and Langmuir adsorption isotherms and various first order kinetic equations at $30 \pm 1^{\circ} \mathrm{C}$. The results suggest that pore diffusion i.e. intra particle diffusion is more important. Adsorption behaviour is described by a monolayer Langmuir type isotherm. The adsorption process is found to be first order with intra particle diffusion, as one of the rate determining steps. The present study concludes that ICO and CC could be employed as low cost adsorbents as alternative to CAC for the removal of AV.

\section{ACKNOWLEDGEMENTS}

The authors are highly thankful to the Management and the Principal of ANJA College, Sivakasi for providing research facilities and constant encouragement. The authors also thank UGC New Delhi and SERO, UGC, Hydrabad, India for providing financial assistance, to one of them (N.K.).

\section{REFERENCES}

1. Adamson A.W. (1960) Physical Chemistry of Surface, Inter Science Publ. Inc., New York, pp. 777.

2. Annadurai G and Krishnan M.R.V. (1996) Adsorption of basic dye using chitin, Indian J. Environ. Protec., 16(6), 444-449.

3. Deo N. and Ali M. (1997) Adsorption by a new low cost material: Congo Red 1 and 2, Indian J. Environ. Protec., 17(5), 328-331.

4. Hall K.R., Eagletow L.C., Acrivers A., and Vermenlem T. (1966) Pore and Solid kinetics in fixed-bed adsorption under constand pattern condition, Ind. Engg. Chem. Fund., 5, 212-218.

5. Kannan N. (1991) A study on removal of nickel by adsorption on fly ash, Indian J. Environ. Protec., 11(7), 514-518. 
6. Kannan N. and Karuppasamy K. (1998), Low cost adsorbents for the removal of phenyl aceticacid from aqueous solution, Indian J. Environ. Protec., 18(9), 683-690.

7. Kannan N. and Xavier A. (2001) New composite mixed adsorbents for the removal of acetic acid by adsorption from aqueous solution-A comparative study, Toxic. Env. Chem., 79, 95107.

8. Kannan N. and Meenakshisundaram M. (2001) Kinetics and Mechanism of removal of methylene blue by adsorption on various carbon - A comparative study, Dyes and Pigments, 51, 25-40.

9. Kannan N. and Rajakumar A. (2001) Studies on the removal of lead (II) ions by adsoption on indigenously prepared activated carbon, J. Env. Stud. Policy, 4, 75-86.

10. Kannan N. and Meenakshisundaram M. (2002) Adsorption of congo red on various activated carbons-A comparative study, Water, Air, Soil Pollut., 138, 289-305.

11. Kannan N. and Rajakumar A. (2002) Comparative study of removal of Lead (II) by adsorption on various carbons, Fres. Env. Bull., 11(3), 160-166.

12. McKay G., Otterburn M.S. and Aga J.A. (1985) Fuller's earth and fired clays as adsorbents for dyestuffs-equilibrium and rate studies, Water, Air, Soil Pollut., 24, 307-322.

13. McKay G. (1983) The adsorption of dyestuff from aqueous solution using activated carbon: analytical solution for batch adsorption based on external mass transfer and pore diffusion, Biochem. Eng. J., 27, 187-194.

14. Pollard S.J.T., Fowler G.D., Sollars C.J. and Perry R. (1992) Low cost adsorbents for waste and wastewater treatment: a review, The Sci. Total Environ., 116, 31-52.

15. Vinod V.P. (2004) Factors Influencing the Sorption of Organics at Solid/Liquid Interface: Mass Transfer Process and Equilibrium Studies, Ph.D. thesis, University of Kerala, pp. 109.

16. Weber W.J. and Morris J.C. (1964) In: Eckenfelder W. W. (ed.), Advances in water pollution research, Pergamon Press, Oxford. 